\title{
Evaluation of agricultural ecosystem services in fallowing land based on farmers' participation and model simulation
}

\author{
Yen Lan Liu • Kang-tsung Chang · Jetse Stoorvogel • \\ Peter Verburg • Chin Hong Sun
}

Received: 11 January 2011/Revised: 21 June 2011/Accepted: 21 June 2011/Published online: 10 August 2011

(C) The Author(s) 2011. This article is published with open access at Springerlink.com

\begin{abstract}
Fallowing with green fertilizer can benefit agricultural ecosystem services (AES). Farmers in Taiwan do not implement fallow practices and plant green fertilizer because the current subsidy level (46,000 NT\$ per ha) is too low to manage fallowing. This paper defines the objective of government agriculture policy or the farmer's objective as maximization of farm productivity, approximated to the value of social welfare and AES. Farms, which do not follow proper fallowing practices, often have poorly maintained fallow land or left farmland abandoned. This results in negative environmental consequences such as cutworm infestations in abandoned land, which in turn can affect crops in adjacent farmlands. The objectives of this study are twofold. First, it determines the proper fallowing subsidy based on the concept of payment for ecosystem services to entice more farmers to participate in fallowing. Second, it simulates the benefit of planting green manure in fallow land to the supply of AES based on the rate of farmers who are willing to participate in fallow land practices and essential parameters that can affect soil fertility change. The approach involves a series of interviews and a developed empirical model. The value of AES when the rate of farmer participation is $100 \%$ represents a $1.5 \%$ increase in AES $(448,317,000 \mathrm{NT} \$)$ over the value at the
\end{abstract}

\footnotetext{
Y. L. Liu · K. Chang · C. H. Sun

Geography Department, National Taiwan University, Taipei, Taiwan

J. Stoorvogel $(\bowtie)$

Land Dynamics, Wageningen UR, Wageningen,

The Netherlands

e-mail: Jetse.Stoorvogel@wur.nl

P. Verburg

VU University Amsterdam, Amsterdam, The Netherlands
}

current participation rate of $14 \%$. This study further concludes that the appropriate fallowing subsidy has a large positive impact on AES and social welfare (e.g., benefit from food and biofuel supplies) and is seen as a basis of ecological governance for sustainable agro-ecosystems.

Keywords Agricultural ecological services - Payment for ecological services · Fallow · Soil fertility · Taiwan · Sustainable agriculture policy

\section{Introduction}

In this paper, agricultural ecosystem services (AES) are defined as benefits people derive from agricultural ecosystems, including food and resources, regulation of climate and disease, support through processes such as crop pollination, and cultural services such as recreation (Daily 1997; Millennium Ecosystem Assessment 2003). To promote fallow land management and the supply of AES, payment for ecosystem services (PES) has been used as an incentive in recent years (Antle et al. 2007). However, for PES to be successful, an appropriate level of incentive is needed (Tilman 2002). Also needed is a new priority in government policy because incentives often favor increased agricultural production at the expense of ecosystem services.

Nevertheless, several negative consequences can also result from unsuitable fallowing practices. Farms that are left fallow but poorly maintained or that are planted with green fertilizer but allowed to become overgrown with weeds can negatively impact surrounding farms. As an example, such farms can become havens for pests such as rats or cotton worms, which infest neighboring properties, reducing overall farm productivity. Further, very poorly maintained farmland functions much the same as abandoned farmland, 
producing negative externalities such as runoff and soil degradation in down-slope areas (Harden 2001).

In Taiwan, farm subsidies in the past have favored the planting of green fertilizer in fallow fields to improve soil fertility. However, over the past 5 years, the Taiwanese government has also encouraged farmers to use fallow fields for the planting of energy crops (e.g., soybeans and sugarcane) and food crops (e.g., rice), as food and energy security have become agricultural policy priorities. A practice essential for sustainable agricultural ecosystems is fallow land management because fallow periods traditionally serve to restore and improve soil fertility for next cultivation period (Heerink 2005). Therefore, it is important to re-examine fallowing and its benefits.

This paper focuses on government policy that encourages farmers to manage fallow fields through farm subsidies. One issue is the subsidy gap. This occurs when subsidies do not meet the cost to farmers of leaving productive land fallow. This kind of policy can result in land abandonment. Another issue is an inappropriate pricing of fallow lands' contribution to soil productivity and the resulting improved supply of ecological services. Thus, the objectives of this paper are (1) to examine how subsidies can be determined based on PES to entice more farmers to participate in fallowing and (2) to propose effective ways of improving the supply of AES. It is believed that appropriate government subsidy cannot only reflect the true value (profit) of ecosystem services but also achieve social welfare.

\section{Literature review}

Agricultural ecosystem service

Society receives many ecosystem service benefits from natural and managed ecosystems (Daily 1997). Ecosystems provide food, fiber, fuel, and materials for shelter; additionally, they provide a range of benefits that are difficult to quantify and that have rarely been priced (National Research Council 2000; Daily 2000). One exception is Antle and Stoorvogel (2006), which used empirical models to quantify non-marketable ecosystem service from agriculture.

Throughout the world, the focus of agricultural policy is shifting away from traditional subsidy and trade policies toward conservation and the environmental aspects of agriculture. This change in perspective has caused agriculture to be viewed as a managed ecosystem, and the ecosystem services provided by agriculture are known to depend on agricultural land and associated management practices. Agricultural ecosystems rely on a suite of supporting ecosystem services to provide food, fiber, and fuel as well as a range of accompanying but non-marketable ecosystem services. Ecosystem services from agriculture include the regulation of water and climate systems, aesthetic and cultural services, and enhanced supporting services such as soil fertility (Swinton 2007).

Soil fertility, fallowing, and abandoned land

Fertile soil with good physical properties to support root growth is essential for sustainable agriculture. Soil infertility is frequently cited as a constraint to crop production in the tropics (Jordan 1985; Sanchez and Logan 1992; Warner 1991). Organic matter is an indicator of soil fertility. On average, organic matter makes up less than $2 \%$ of paddy land in subtropical areas ( $\mathrm{Gu} 2006)$, and its seasonal rate of consumption is within the range of $1.5-3.2 \%$ if green manure is not implemented (Sheng 2005). On the other hand, planting green fertilizer, such as Indian Sesbania, can improve the percentage of organic matter in paddy land (Nambiar and Abrol 1989).

In a comparative study of land fertility in Taiwan for the period from 1995 to 2000, Lo (2009) proposed that fallow land when planted with green fertilizer can have more organic matter by an average of $0.5-1.5 \%$ than organic matter in abandoned land. Lo (2009) also found that the average rice yield after fallowing was $4,506 \mathrm{t} / \mathrm{ha}$, representing a $2 \%$ increase $(88 \mathrm{t} / \mathrm{ha})$ over the yield of non-fallow land $(4,418 \mathrm{t} / \mathrm{ha})$. Every year, pest damage due to abandoned land causes an average loss of up to $15 \%$ in production during the first growing season and 30\% during the second. French (1978) suggested that mean grain yield after fallowing was $1,515 \mathrm{~kg} / \mathrm{ha}$, representing a $31 \%$ increase $(355 \mathrm{~kg} / \mathrm{ha})$ over the non-fallow yield of $1,160 \mathrm{~kg} / \mathrm{ha}$. The effects of land degradation on productivity can sometimes be compensated for by increased fertilization, irrigation, and disease control, which in turn increase production costs. Moreover, the increased use of fertilizers can contribute to environmental problems such as the eutrophication of aquatic habitats (Cassman 1999).

It is evident from the above discussion that fallow periods play an integral role both in improving soil productivity and in increasing ecosystem services. It is also evident that soil productivity can be improved by the planting of green manure and legumes during fallow periods. A further benefit from fallow periods is the conservation of biodiversity (Fu 1995). In light of these facts, agricultural policy needs to be directed so as to maximize both the social value of appropriate land use and the output of conventional agricultural products in order to reap all the benefits AES can provide (Antle et al. 2007).

The importance of information collection in understanding farmers

Farmers are key stakeholders in agricultural issues. This means that understanding their behavior and attitudes is an 
essential priority in designing appropriate agricultural policy. One means of acquiring information on farmer motivations is the interview process. Beedell (2000) used an interview process based on a social-psychological model, the Theory of Planned Behavior, to collect information regarding farmers' conservation-related behavior in Britain. Potter and Lobley (1996) conducted interviews with farmers throughout Britain in 1993 to identify highand low-landscape-change farms, in terms of environmental stock, and to examine the relationship between farm business development and environmental change. In a study on the implementation of a PES scheme, in case of farming practices that were resulting in an increased nitrates in the aquifer of Vittel, Perrot-Maitre (2006) proposed the following four-step approach to understanding the historical influences, geography, and social factors that influence farming practices:

1. Understand the relevant farming systems and why farmers do what they do.

2. Analyze the conditions under which farmers would consider changing farming practices.

3. Identify, test, and validate in farmers' fields the management practices necessary to reduce the nitrate threat.

4. Provide financial and technical support to farmers who are willing to enter the program.

\section{Farmer participation and incentive mechanisms}

Farmer participation in more environmentally friendly farming methods can be encouraged through agricultural policy by regulating farming to incorporate certain practices. However, ensuring the success of a regulatory approach is not a simple undertaking given that many environmental problems and ecosystem services are difficult to monitor and quantify (Tilman 2002). PES is an alternative to an adversarial regulatory approach in resource management. PES provides positive incentives for farmers to preserve environmental resources. While a PES system also requires monitoring and verification of compliance with contracts to provide ecosystem services, it allows for a more positive relationship between farmers and the government (Nalukenge 2006). Several policy initiatives have attempted to balance the needs for agricultural production and for ecosystem services. Jack (2008) emphasized that because PES programs are incentive based, policymakers can draw on farmers' substantial body of knowledge. Further, PES schemes offer a direct method for achieving environmental outcomes that is possibly more equitable than other approaches. Antle and Stoorvogel (2008) also suggested that governments use tax revenues to pay landowners to manage lands in ways that can protect or enhance the provision of ecosystem services. This paper makes a similar proposal for using tax revenues to subsidize farmers' management of their fallow land. The success of environmental projects requires that policymakers take into account the factors that determine farmers' land management decisions. If policymakers do not consider these factors, such programs tend to fail after the intensive technical assistance, special incentives, and subsidies provided by the government are no longer available, as was noted by Barbier (1997).

\section{Linear programming}

A number of empirical models and approaches have been designed to assess optimal farm production based on farmer decisions. Linear programming models try to satisfy a set of goals that are compatible with preferences revealed by farmers (Sumpsi 1996). Massell and Johnson (1968) emphasized the necessity of profit maximization in resource use on the average farm. Huang et al. (2005) discussed the farmers' optimal decision model using a linear programming function with a focus on production costs. Sumpsi (1996) also proposed a multicriteria approach within a linear programming framework to analyze and predict farmer behavior in farm planning and agricultural management.

However, almost all maximization studies of farmers' decisions have focused on economic factors such as production costs, labor input, and land rent rather than on ecosystem services, such as soil fertility. These economic factors might not adequately represent all the externalities that profit-maximizing behavior produces. The cost of those could be borne in reduced AES. Appropriate government policy needs to reflect the true value of ecosystem services and the true costs of particular farming practices. In this paper, the objective of government agricultural policy is defined as the maximization of farm productivity, which is an approximation of the value of social welfare and AES. One area in which this can be achieved is in improving soil fertility by adhering to appropriate fallow practices. Tilman (2002) stated that the goal of sustainable agriculture is to maximize the net benefits to society from the agricultural production of food, fiber, and ecosystem services. Farmer participation is a central issue in achieving sustainable agriculture. Thus, a sustainable agricultural management model should be based on farmer participation with a view toward maximizing ecosystem services.

In the literature review, we saw that soil fertility directly contributes to higher yields and, in turn, to improved human well-being. Therefore, soil fertility can be viewed as representative of a specific aspect of AES; that is, it results in an increased yields, improved human welfare (including farmers' income), and increased ecosystem 
services. This study focuses on three land types: fallow land that is planted with green manure, fallow land that is left abandoned, and land that is cultivated intensively.

\section{Materials and methods}

Data

This study assumed that the total farmland area was 19,637 ha (see Fig. 1), corresponding to the area where interviews of farmers were conducted (see "Interviews of farmers"). The total area was needed as a parameter for a constraint function in the AES model. Other input data to the model included net income per hectare from planting of rice (for food), soybean (for energy crop), and rape flower (for green fertilizer; Table 1) and soil fertility parameters with either positive or negative values (Table 2).

\section{Method}

First, we interviewed farmers to obtain information regarding their attitude toward the PES scheme and requirements that are necessary from a policy perspective to improve farmer compliance with fallow land practices.
Second, we used the linear programming approach to develop an AES model centered on soil fertility (Fig. 2). Within this model, farmer participation in fallow land practice is based on either incomplete or complete information on subsidy. The inputs to the model are factors that can either improve or reduce soil fertility depending on farm management practices, and the output is revenue indicative of the value of AES. Land A in Fig. 2 includes two scenarios: fallow land planted with green fertilizer has positive impacts on soil fertility $(+)$ and abandoned fallow land has negative impacts on soil fertility (-). Lands B and $\mathrm{C}$ are intensely cultivated with rice and energy crop, respectively, both impacting soil fertility negatively $(-)$.

\section{Interviews of farmers}

To better understand why farmers abandon fallow fields, this study used a series of interviews to obtain information on how to motivate farmers to participate in fallowing through a PES incentive mechanism. Specifically, this study adopted steps 1 and 2 of the four-step approach proposed by Perrot-Maitre (2006) to find out the level of subsidy that can be accepted by farmers to participate in fallowing. Interviews were conducted in 2009 in Chiayi County, the main agricultural county in Taiwan. According

Fig. 1 Study area

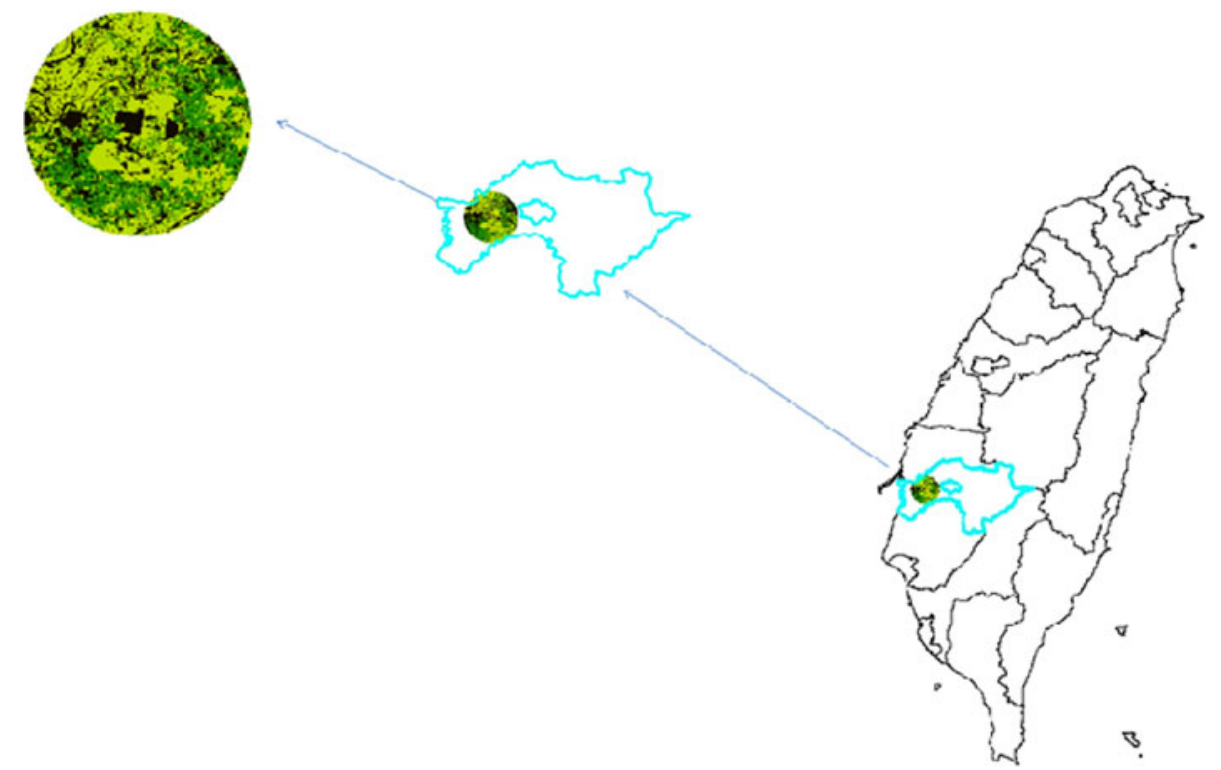

Table 1 Net income of plantings and crops

\begin{tabular}{llll}
\hline Farmland & Type of planting & Net income & Reference \\
\hline Planted for food & Rice & 55,000 & Cheng (2006); Council of Agriculture (COA) (2008) \\
Planted for energy & Sugarcane & 74,300 & \\
Fallow & Rape flower as green fertility plant & 38,000 & \\
\hline
\end{tabular}


Table 2 Parameters affect soil fertility in the AES model

\begin{tabular}{lllll}
\hline Parameter & $\alpha$ & $\theta$ & $\delta$ & $\sigma$ \\
\hline Effect on soil fertility & Negative (-) & Negative (-) & Negative (-) & Positive (+) \\
Data available & A series of interviews & Huang (2009) & Sheng (2005) & Lo (2009) \\
Data range & PES and adoption & $0.15-0.30 \mathrm{t} / \mathrm{ha}$ & $0.15-0.32 \mathrm{~kg} / \mathrm{ha}$ & $0.02 \mathrm{t} / \mathrm{ha}$ \\
\hline
\end{tabular}

$\alpha$ denotes the percentage of farmers abandoning land, $\theta$ is a parameter denoting a decrease in soil fertility as a result of abandonment, $\delta$ denotes the decline in soil fertility after harvesting crops, and $\sigma$ denotes restoration of soil fertility by fallow practices that contribute to productivity during the ongoing growing season

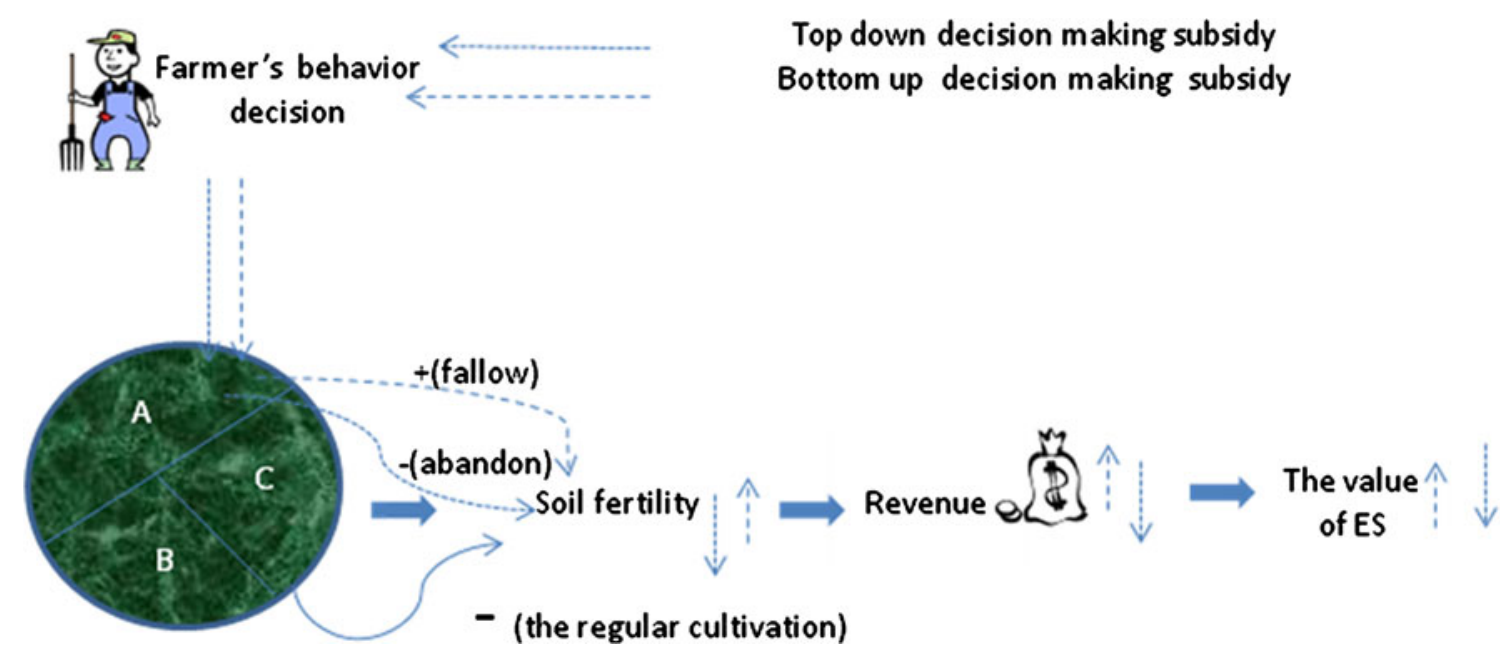

Fig. 2 A schematic of AES model design

to the Chiayi local governmental report (2008), $40 \%$ of households in the county were classified as farming, the average farmer's age was 61 , abandoned fields accounted for $17 \%$ of the county's farmland, and $24 \%$ of farmer's income was from farming revenue.

Using a simple random sample of 525 people, the phone interviews involved 116 farmers from the Chiayi Farmers' Association. Eighty-five percent of these farmers were 60-64 in age and the remainder 55-59. They were asked the following three questions:

1. Is a subsidy key to determining whether you leave land fallow or not?

2. If the subsidy was above the current level, would you then comply with fallow land policy?

3. How much subsidy would you require?

\section{Empirical model to measure the benefit of AES}

Linear programming was used in this study to solve the AES model so that it would achieve the maximum profit for the farmer and the government. Our assumption is that the government has the same objective as the farmer, that is, to maximize the human social welfare and AES.
To combine ecological perspectives with the profit-maximization objective of government policy, the AES model we constructed has an infinite cultivation period constrained by decreased soil fertility due to abandonment and cropping. The objective function uses a logarithm for linear programming since it is a general solution to the dynamic parameter in a time series. Because the AES model focuses on government policy objectives and ecological perspectives, the present value of the time series of cash flows and opportunity cost can be ignored. With input data from Table 1 , the model combining the agent decision and ecological services has the following form:

$$
\begin{array}{rr}
\max R=\sum_{t=1}^{n} \beta^{t-1}\left(P_{R} A_{R, t}+P_{B} A_{B, t}+P_{F} A_{F, t}\right) \\
\text { s.t. } A^{\prime} \geq A_{R, t}+A_{B, t}+A_{F, t}, & \forall t \\
(1-\theta \cdot \alpha) A_{t}^{\prime}=A_{t}, & \forall t \\
Q_{t}+\sigma A_{F, t}-\delta_{R} A_{R, t}-\delta_{B} A_{B, t}=Q_{t+1}, & \forall t \\
A_{R, t}, A_{B, t}, A_{F, t}, A_{t} \geq 0, & \forall t
\end{array}
$$

In the objective function, the maximized production $R$ denotes the value of ecosystem services, optimized by profit from agricultural total production. $P$ denotes the 
profit per hectare, and $A$ denotes cultivating area. $P_{R} \ln A_{R, t}$ denotes the profit of planting rice, $P_{B} A_{B, t}$ for the profit of planting energy crops (e.g., soybeans), and $P_{F} \ln A_{F, t}$ for the profit of planting green fertilizers (e.g., Brassica napus L.). $\beta$ is the discount factor of the infinite series. Two constrained functions can be implied by fluctuation in ecosystem services. In the first and second constrained functions, area for every $t$ period has to be no more than 19,637 ha.

In the second constrained function, the harvest area of farmland varies with the restoration and degradation of soil fertility due to fallowing and abandonment, respectively (Fig. 3). For example, yield diminishes when soil fertility is degraded after farmers decide to abandon land. $A^{\prime}$ represents the reduced harvest area from $\overline{A_{t}}$ because of $\theta \cdot \alpha$, where $\alpha$ denotes the percentage of farmers abandoning land and $\theta$ is a parameter denoting a decrease in soil fertility as a result of abandonment (Roder 1994; Jordan 1985; Sanchez and Logan 1992; Warner 1991). From an ecological viewpoint, $\theta \cdot \alpha$ is the main factor that causes productivity declines and lessened soil fertility. Here, $0 \leq \theta \cdot \alpha<1$. That is, $\bar{A}_{t}$, or total farmland area for period $t$, varies negatively with $\theta \cdot \alpha$ : when $\theta \cdot \alpha$ is greater, $\bar{A}_{t}$ is lower.

In the third constraint function, $Q_{t}$ denotes the production by the improvement of soil fertility. $Q_{t+1}$ is the production of period $t+1$ and its production variation affected by parameters soil fertility. $\sigma$ denotes restoration of soil fertility by fallow practices that contribute to productivity during the ongoing growing season (Wu 2002; Cassman 1999); in contrast, $\delta$ denotes the decline in soil fertility after harvesting crops $\left(\delta_{R}\right.$ denotes the decline after the rice harvest, and $\delta_{B}$ denotes the decline after the harvest of energy crops). In other words, in the third constrained function conducts the area of period summed by the area of period $\mathrm{t}-1$ and its soil fertility variation affected by parameters soil fertility.

The assumptions with regard to which parameters have a positive or negative effect on soil fertility are presented in Table 1. Table 1 illustrates parameters used to formulate AES. These parameters have a positive or negative effect on soil fertility. $\alpha$ represents percentage of farmers abandoning land; if $\alpha$ is small, it means a positive effect on soil fertility because through fallow land practices farmers are restoring soil fertility and contributing positively to productivity during the growing season (Gu 2006; Lo 2009). $\theta$ and $\delta$ illustrate the negative effects on soil fertility. $\theta$ represents a loss to production on average due to pest damage (Huang 2010), and $\delta$ represents decline in soil fertility after regular cropping (Sheng 2005).

Genetic Algorithm (GA) is one of a family of heuristic optimization techniques, which include simulated annealing, Tabu search, and evolutionary strategies. This study
Fig. 3 The relationship of soil fertility and harvest area

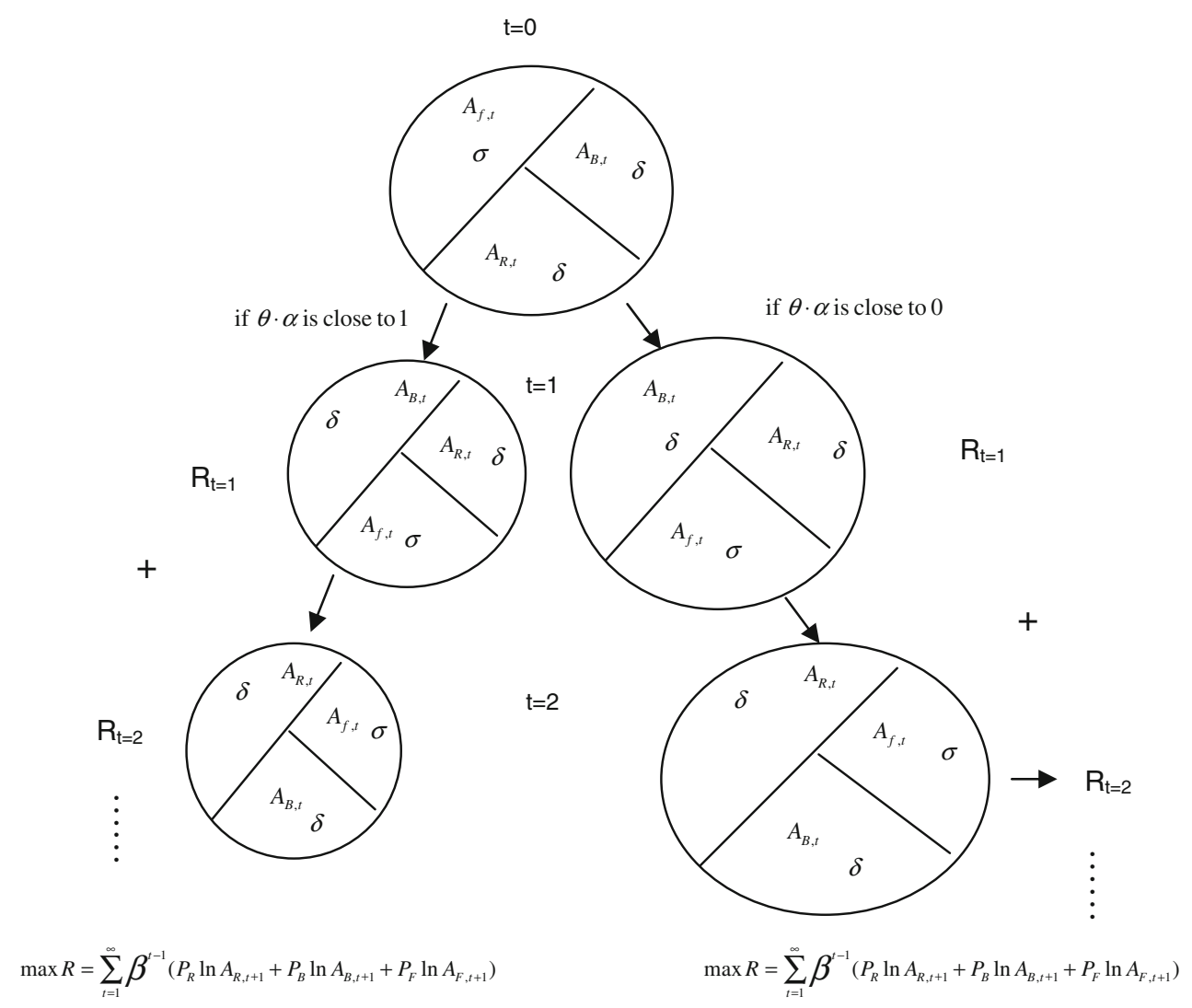


adopted GA because the technique has been demonstrated to converge to the optimal solution for many diverse applications (Coit 1996). The value of AES can be affected by a variety of factors, of which the rate of farmer participation in fallow, amount of subsidy, and soil fertility are the factors considered in this study.

\section{Results and discussions}

Interview results

Some farmers said that serious cutworm damage occurred when planting green fertilizer on fallow land, requiring a lot of money for pest control. To them, the cost of fallow management was not affordable in the long term. Others stated that farm income had been declining with decreased productivity, most young people were not willing to work in agriculture, and they were too old to pursue pest control during fallow periods. In addition, for those farmers who were complying with fallow regulations at the time of interview, the subsidy was not really enough to support the fallow.

In terms of the sampling statistics or the subsidy requirement for maintaining fallow fields, 16 out of 116 interviewed farmers were willing to accept 46,000 NT\$; 42, 47,500 NT\$; 28, 48,500 NT\$; 20, 49,500 NT\$; and 10, 50,000 NT\$.

Quantifying the benefits of fallow land to AES

\section{Rate of participation on AES}

The rate of farmer participation in fallow practices can affect the value of AES. Using the results from the interviews, we estimate the value of AES, in thousands of NT\$, to be $28,197,068$ at $14 \%$ participation $(\alpha=0.86), 28,392,327$ at $50 \%$ participation $(\alpha=0.5), 28,516,249$ at $74 \%$ participation $(\alpha=0.26), 28,601,265$ at $91 \%$ participation $(\alpha=0.09)$, and $28,645,385$ at $100 \%$ participation $(\alpha=0$; Fig. 4$)$. In other words, $100 \%$ participation represent a $1.5 \%$ increase in AES (448,317,000 NT\$) over 14\% participation.

\section{Soil fertility on AES}

Based on the results from GA, Fig. 5 shows the changes in AES values due to declined soil fertility after regular harvesting of crops. The AES value, in thousands of NT\$, drops from $28,197,080$ to $28,197,056$ as the index $\delta$ increases from 0.15 to 0.32 . Figure 6 depicts the trend line of decreasing AES values with increasing $\delta$.

Figure 7 illustrates the changes in AES values due to declined soil fertility with abandoned land. The AES value, in thousands of NT\$, decreases from 28,197,064 to

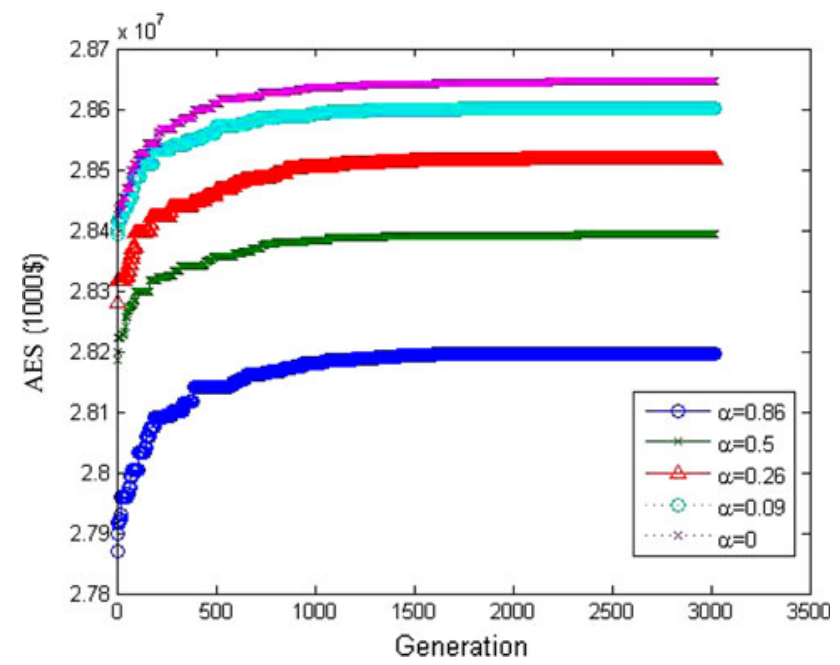

Fig. 4 Simulation results showing the effect of fallow participation rate on AES

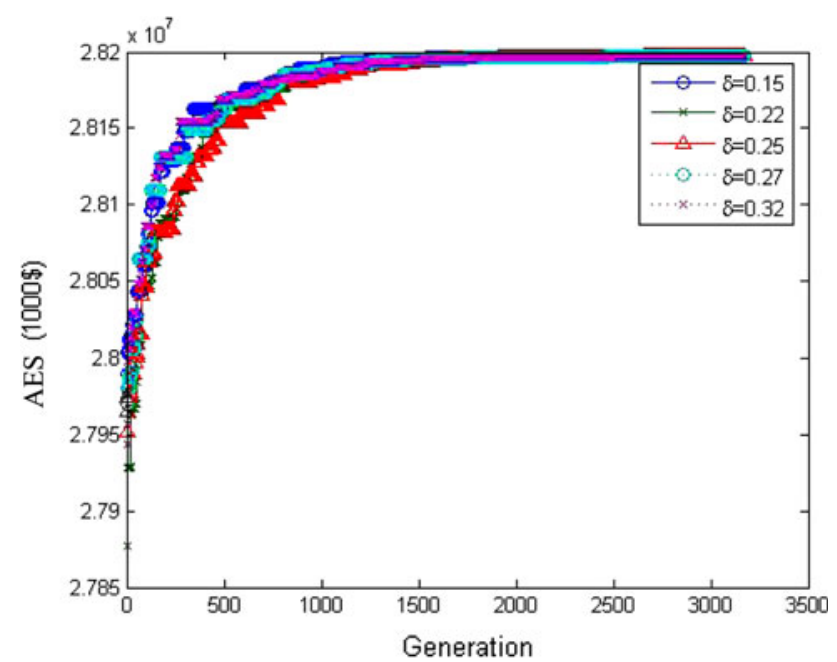

Fig. 5 Simulation results showing the effect of soil fertility after regular crop harvesting $(\delta)$ on AES

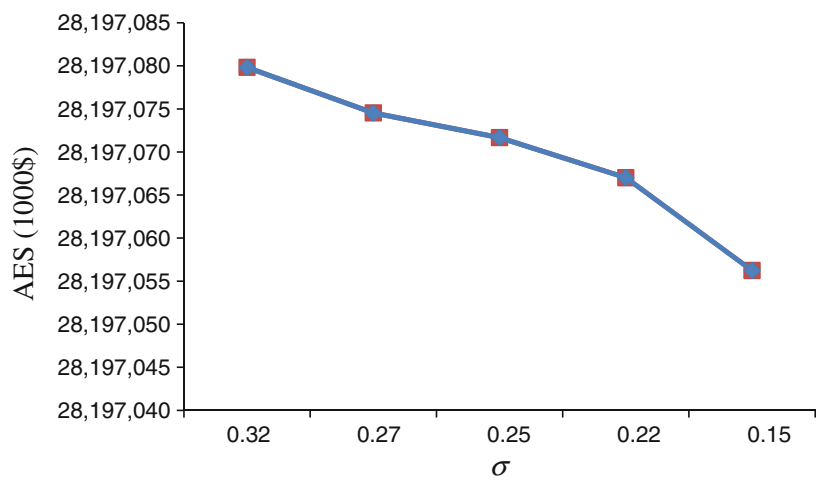

Fig. 6 Trend line showing the effect of soil fertility post regular cropping on AES 


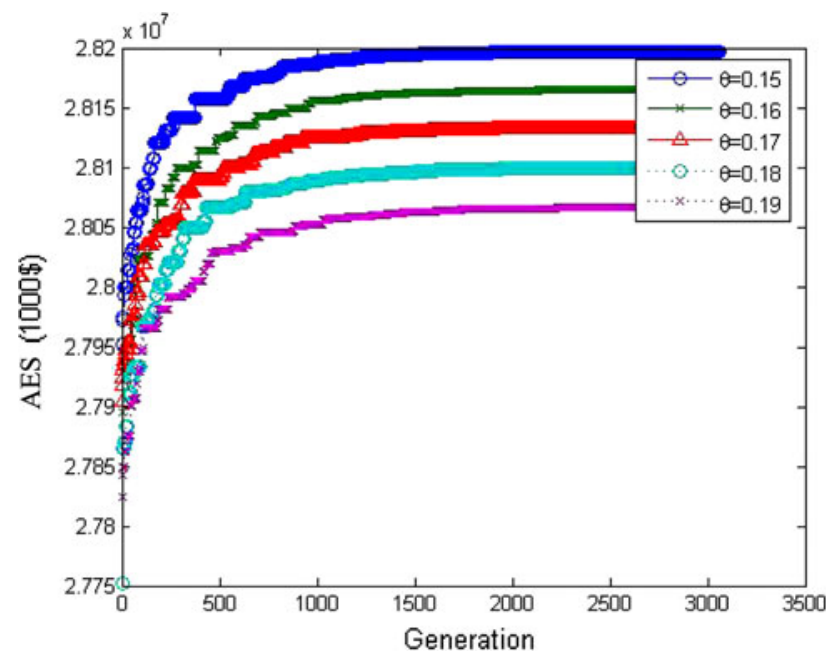

Fig. 7 Simulation results showing the effect of abandoned land $(\theta)$ on AES

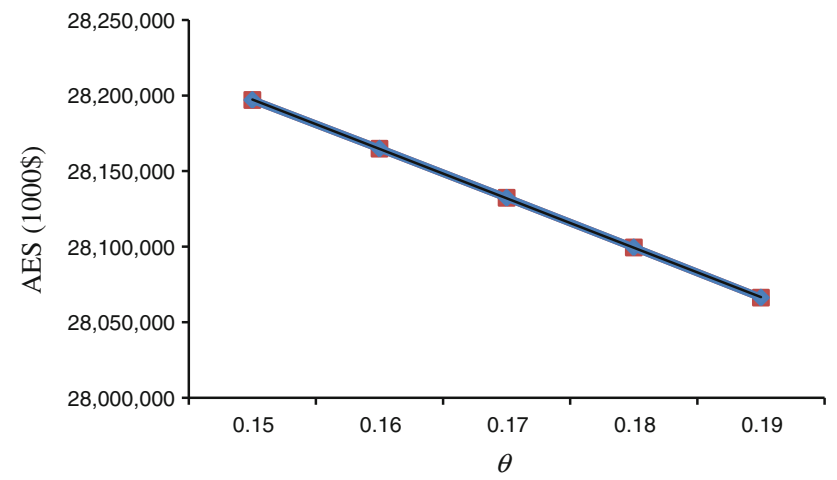

Fig. 8 Trend line showing the effect of abandoned land on AES

$28,066,272$ as the index $\theta$ increases from 0.15 to 0.19 . Figure 8 shows the trend line relating the two variables.

Figure 9 shows the changes in AES values due to restored soil fertility by fallowing. The AES value, in thousands of NT\$, increases from $28,197,068$ to $28,197,078$ as the index $\sigma$ increases from 0.02 to 0.09 . The trend line relating the two variables is depicted in Fig. 10. Figures 9 and 10 therefore suggest that soil fertility restored by fallowing can increase the overall production, thus improving the value of AES. On the other hand, the contribution in this paper is that the value of ecosystem services can be measured with the profit.

Changes in AES in Figs. 5 and 9 are relatively smaller in percentage than Fig. 7. This implies that the effect of the parameter $\theta$ on AES is more sensitive than the parameters $\delta$ and $\sigma$.

In summary, the results show that provisioning for fallow land and planting with green manure improves biocapacity and increases farm profits within a governing parameter $(\sigma)$ by restoring soil fertility. Fallowing exists whether benefit from fallowing is significant or not. Based on the result, this study proposes a hierarchical relationship

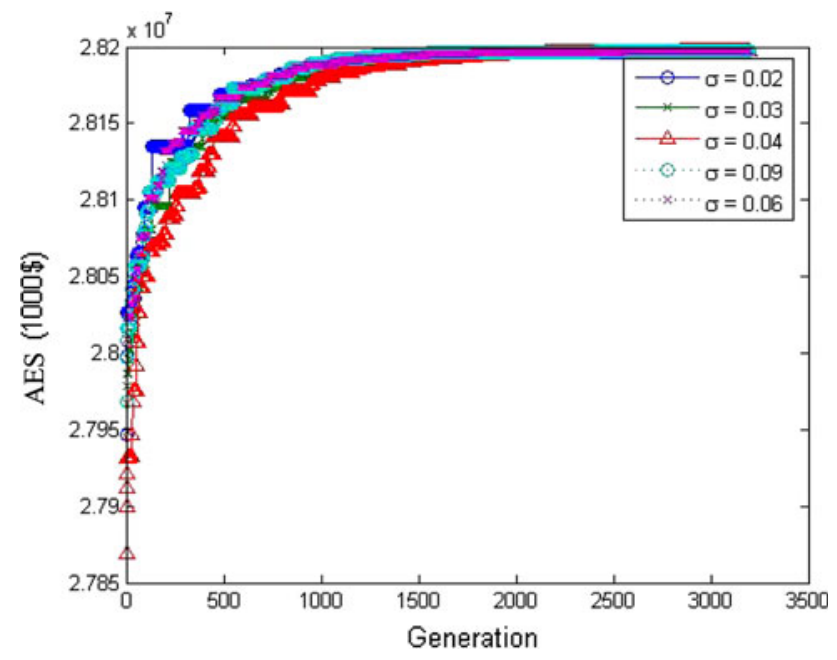

Fig. 9 Simulation results showing the effect of soil fertility restored by fallowing $(\sigma)$ on AES

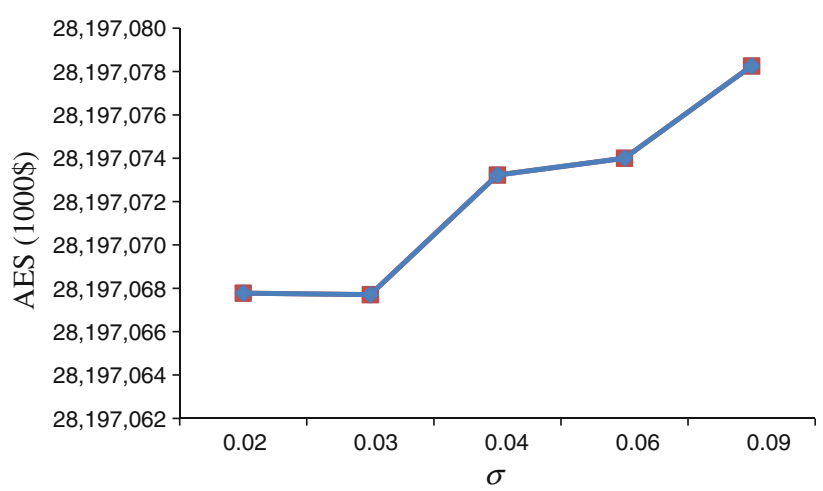

Fig. 10 Trend line showing the increase in AES with soil fertility restored by fallowing

to achieve sustainable agricultural land use (Fig. 11). Moreover, increasing subsidy is the basic component to improve AES. It can contribute indirectly to the AES through the farmers' participation in fallow. Thus, it can be said that the increased AES is generated from farmers' participation in fallow to reduce environmental negative externalities. These results should be of use to future agricultural policy making, especially with respect to the advantages afforded by AES. In this case, appropriate farm policy could have both ecological and economic advantages. From an ecological viewpoint and for greater farmer productivity, farmers would benefit from planting more fallow land with green manure to maintain soil fertility.

\section{Conclusion}

This study has examined how PES can improve AES and the benefits derived from them. In particular, it has 


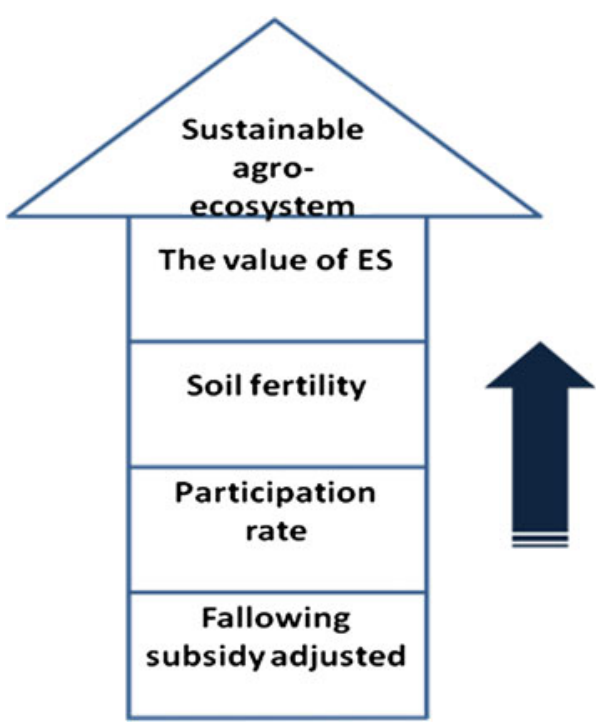

Fig. 11 A schematic on how to achieve sustainable agro-ecosystem

examined soil fertility and how the practice of leaving land fallow can improve crop yields and AES. The results show that the right incentives can help in maximizing the total return to society when appropriate agricultural practices are undertaken. Clearly, it is worth emphasizing that an incentive subsidy based on PES is an effective mechanism. However, the pricing of incentives requires an understanding of farmer behavior in order to improve participation in fallowing practices. In this study, this understanding was achieved through an interview process, which examined the underlying issues for farmers, such as changing demographics and a subsidy gap, which exists between the present subsidy and the cost of maintaining fallow practices. In areas where crop rotations include a fallow of one or more years, there are multipurpose uses of legumes-to regenerate soil fertility, provide high-quality forage, and reduce the labor costs of initiating the following cultivation cycle (IRRI 1988). We therefore conclude that a well-priced incentive aimed at maximizing the value of ecosystem services can lead to substantial social benefits due to a more complete understanding of farmer motivations. At the same time, planting green fertilizer during fallow periods to restore soil fertility improves the supply of agriculture ecosystem services. We further conclude that fallowing based on farmers' participation has a large positive effect on AES and on factors that affect human social welfare, such as the food and biofuel supplies. In short, appropriate government subsidy not only reflects the true value of ecosystem services but also achieves social welfare.

Acknowledgment The authors wish to acknowledge Cheng Young Lyu and Sam Lai for their assistance.
Open Access This article is distributed under the terms of the Creative Commons Attribution Noncommercial License which permits any noncommercial use, distribution, and reproduction in any medium, provided the original author(s) and source are credited.

\section{References}

Antle JM, Stoorvogel JJ (2006) Predicting the supply of ecosystem services from agriculture. Am J Agric Econ 88(5):1174-1180

Antle JM, Stoorvogel JJ (2008) Agricultural carbon sequestration, poverty, and sustainability. Environ Dev Econ 13(3):327-352

Antle JM, Capalbo SM, Paustian KH, Ali MK (2007) Estimating the economic potential for agricultural soil carbon sequestration in the Central United States using an aggregate econometricprocess simulation model. Clim Change 80(2):145-171

Barbier EB (1997) The economic determinants of land degradation in developing countries. Philos Trans R Soc Ser B 352:891-899

Beedell J, Rehman T (2000) Using social-psychology models to understand farmers' conservation behaviour. J Rural Stud 16: $117-127$

Cassman KG (1999) Ecological intensification of cereal production systems: yield potential, soil quality, and precision agriculture. Proc Natl Acad Sci USA 96:5952-5959

Cheng B (2006) The assessment of external economic benefit in developing energy crops. Agriculture and Food Agency, Council of Agriculture

Chiayi local governmental report (2008) Chiayi local governmental publication, Taiwan

Coit DW, Smith AE (1996) Reliability optimization of series-parallel systems using a genetic algorithm. IEEE Trans Reliab 45(2): 254-260

Council of Agriculture (COA) (2008) Yearly report of Taiwan's agriculture. Council of Agriculture, Executive Yuan

Daily GC (1997) Nature's services: societal dependence on natural ecosystems. National Academy Press, Washington

Daily GC (2000) The value of nature and the nature of value. Science 289:395-396

French RJ (1978) The effect of fallowing on the yield of wheat: II. The effect on grain yield. Aust J Agric Res 29:669-684

Fu B, Chen L (1995) Landscape diversity types and their ecological significance. Acta Geogr Sin 15(4):343-350

Gu GW (2006) Organic fertility affects production and growing of the snap bean in fall season. Taiwan Agricultural Report

Harden CP (2001) Soil erosion and sustainable mountain development: experiments, observations, and recommendations from the Ecuadorian Andes Mountain research and development. Mt Res Dev 21:77-83

Heerink N (2005) Soil degradation in sub-saharan Africa. Land Use Policy 22:67-74

Huang CH (2005) Assessment of transforming rice land to energy crop land. The proceeding of workshop of agricultural diversity, pp 223-240

Huang SL (2009) Taiwan rice insect pests prevention and treatment trends and prospects. Taiwan rice conservation outcomes and a new outlook symposium special issue, pp 131-147

Huang SH, Cheng CH, Wu WJ (2010) Possible impacts of climate change on rice insect pests and management tactics in Taiwan. Crop Environ Bioinfo 7:269-276

IRRI (1988) Vector-borne disease control in humans through rice agroecosystem management. WHO/FAO/UNEP Panel of Experts on Environmental Management for Vector Control. International Rice Research Institute, Los Banjos, Philippines, p 237 
Jack BK, Kouskya C, Sims KRE (2008) Designing payments for ecosystem services: lessons from previous experience with incentive-based mechanisms. PNAS 105:9465-9470

Jordan CF (1985) Nutrient cycling in tropical forest ecosystems. Wiley, New York

Lo Q (2009) Soil management techniques II on Fallow paddy field in northern Taiwan. Publication of Council of Agriculture Taiwan

Massell BF, Johnson RWM (1968) Economics of smallholder farming in Rhodesia: a cross-section analysis of two areas. Food Res Inst Stud Suppl 8:74

Millennium Ecosystem Assessment (2003) Ecosystems and human well-being: a framework for assessment. Island Press, Washington, DC

Nalukenge I, Antle JM, Stoorvogel J (2006) Assessing the feasibility of wetlands conservation: using payments for ecosystems services in Pallisa, Uganda. Nat Resour Manag Policy 31:239-253

Nambiar KKM, Abrol IP (1989) Long-term fertilizer experiments in India: an overview. Fertilizer News 34:11-20

National Research Council (NRC) (2000) Toxicological effects of methylmercury. Committee on the toxicological effects of methylmercury, Board on environmental studies and toxicology, Commission on life sciences, National Research Council. National Academy Press, Washington, DC

Perrot-Maitre D (2006) The Vittel payments for ecosystem services: a "perfect" PES case? IIED, London
Potter C, Lobley M (1996) The farm family life cycle, succession paths and environmental change in Britain's countryside. J Agr Econ 47:172-190

Roder W, Phengchanh S, Keoboulapha B (1994) Relationships between soil, fallow period, weeds and rice yield in slash-andburn systems of Laos. Plant Soil 176:27-36

Sanchez PA, Logan TJ (1992) Myths and science of the tropics. Soil Sci Soc Am Special Publ 9:35-46

Sheng SS (2005) The effect of paddy field weeds for different rotation systems. Hualien Zone Res Rep 14:79-94

Sumpsi JM, Amador F, Romero C (1996) Theory and methodology on farmers' objectives: a multi-criteria approach. EJOR 25(1): 64-71

Swinton SM, Lupi F, Robertson GP, Hamiltond SK (2007) Ecosystem services and agriculture: cultivating agricultural ecosystems for diverse benefits. Ecolog Econ 64:245-252

Tilman D, Cassman KG, Matson PA, Naylor R, Polasky S (2002) Agricultural sustainability and intensive production practices. Nature 418:671-677

Warner K (1991) Shifting cultivators-local technical knowledge and natural resource management in the humid tropics. Community Forestry Note 8 . FAO, Rome, p 80

Wu MC (2002) Planning the policy of agricultural land release for long, medium and short-term. Chinese Institute of Rural Development Planning 